\title{
Production of Intensifying Blue Light by Cherenkov Radiation Phenomena and Their Use as Power Source Applications
}

\author{
Shima El-Shemy \\ Beni Suef University \\ Mostafa Eissa \\ beni suef university \\ Aly Arafa ( $\sim$ arafaaly@aucegypt.edu ) \\ Beni Suef University
}

\section{Research Article}

Keywords: blue light, Cherenkov radiation, PhCs, reflectance, Transmittance

Posted Date: March 30th, 2021

DOl: https://doi.org/10.21203/rs.3.rs-344211/v1

License: (c) (i) This work is licensed under a Creative Commons Attribution 4.0 International License.

Read Full License 


\title{
Production of intensifying blue light by Cherenkov radiation phenomena and their use as power source applications
}

\author{
S.M.El-Shemy ${ }^{\mathrm{a}}$, M.F.Eissa ${ }^{\mathrm{a}}$, and Arafa H. Aly ${ }^{(*, b)}$ \\ ${ }^{a}$ Nuclear and Radiation Physics Research Laboratory, Physics Department, Faculty of \\ Science, Beni-Suef University, Beni-Suef City 62511, Egypt. \\ ${ }^{\mathrm{b}}$ TH-PPM group, Physics Department, Faculty of Science, Beni-Suef University, Egypt. \\ * Corresponding Author: arafaaly@aucegypt.edu \& arafa16@yahoo.com
}

\begin{abstract}
It is interesting to note in recent years for a large number of researchers the topic of photonic crystals (PhCs) because of their new and useful properties. In addition, there are many advantages to photonic crystals materials as a high reflectance materials as well as the high transmittance materials based on the target application. The calculations were done for Aluminum oxide and titanium oxide $\left(\mathrm{Al}_{2} \mathrm{O}_{3} / \mathrm{TiO}_{2}\right)$ composite photonic crystal in one dimension, which shows a high reflectivity $(\sim 99 \%)$. The chosen photonic crystal composite can be useful to reflect the Cherenkov light many times which comes out from Cherenkov radiation by using radioisotope ${ }^{90} \mathrm{Sr}-{ }^{90} \mathrm{Y}$. The output intensified light has power $1.45 \mu$ watt and 1.45 nwatt for ${ }^{90} \mathrm{Sr}-{ }^{90} \mathrm{Y}$ with the activity $1 \mathrm{Ci}$ and $1 \mathrm{mCi}$ respectively, that can be used for micro/nano-power source applications.
\end{abstract}

Keywords: blue light; Cherenkov radiation;PhCs; reflectance; Transmittance

\section{Introduction}

Recently photonic crystals have great importance in many applications, thanks to the periodic structure of different materials which forming a specific band gap, the optical properties like reflectivity and transmission could be improved.$^{[1,2]}$. Cherenkov radiation is interesting phenomenon to 
act as a detector for charged objects using light emission to measure the velocity of the beta particle and used in various applications. Cherenkov counters can used in nuclear physics detectors and accelerators as well as in nuclear reactors, cosmic rays, particle astrophysics, biomedicine and biological molecules ${ }^{[3]}$.

Photonic crystals (PCs) feature is due to the interaction of ectromagnetic waves propagations with the matter which the contrast in refractive index. Also, the structure arranged periodically in one, two and three dimensions using artificial materials. ${ }^{[4]}$ The unique feature of PCs is photonic band gap (PBG) which are appeared and control control of the electromagnetic waves as well as make a photon localization easy which consider a great importance in the optical and photonic communities ${ }^{[5]}$. PBGs are prohibited frequency regions that offer an good efficient control on the electromagnetic waves propagation because the destructive interference at the interfaces of the constituent materials. ${ }^{[6]}$

Photonic crystals structure of high reflectivity and high transmittance were designed using a periodic structure of different materials. Cherenkov radiation makes several reflections by the designed PCs which lead to an increase in the intensity of the final beam. The beam is guided to a window made of materials that have a high light transmission to keep the outcome radiation passing without decreasing the intensity, and thus increase the blue light power.

We aim to fabricate a photonic crystal structure that works to reflect all the emitted Cherenkov photons and intensify the blue light produced by Cherenkov radiation phenomena, then all the intensified light pass without losing its energy through the window made from high transmittance photonic crystal which can be used for some applications. 
One of these applications is to use the intensified photons as a micro/nano-watt power source.

\subsection{Cherenkov radiations}

Cherenkov radiations $(\mathrm{CR})$ can producing if a charged particle travels within a transparent medium (liquid or solid) with a speed greater than the speed of light in the same medium ${ }^{[7]}$. The CR can extend from ultraviolet (UV) to visible light which is their spectrum have a maximum at $420 \mathrm{~nm}^{[8]}$. Thus, the radiation is within the detection range (with a maximum sensitivity at wavelength $\sim 420 \mathrm{~nm}$ ) of the photomultiplier tubes of a liquid scintillation counter (LSC). CR photon emission is due to the local polarization along the path of travel of the charged particle with the electromagnetic radiation emission when the polarized molecules return to their original states ${ }^{[9]}$. The $\mathrm{CR}$ is propagated as a conic wavefront, Which are the radiation is emitted as a cone in the direction of particle travel ${ }^{[10]}$.

The measurement process of CR by LSC is called the Cherenkov counting technique. The energy threshold of a radionuclide for Cherenkov counting in water is $0.263 \mathrm{MeV}^{[8]}$. Thus, ${ }^{90} \mathrm{Sr}$ and ${ }^{90} \mathrm{Y}$, with maximum beta energies of $0.546 \mathrm{MeV}$ and $2.280 \mathrm{MeV}$, respectively, are above the threshold energy. Therefore, making the Cherenkov counting technique a convenient radionuclide testing technique. The threshold energy for Cherenkov production will change according to the medium refracteive index and will be lower for media of higher index of refraction.

Some time they used ${ }^{[11]}$ employ the $\mathrm{CR}$ in the measurement of radioactivity and different applications, especially when CR are produced at significant levels. For the medical applications, therapeutic photon, 
proton and gamma-ray beams can be obtained by measuring the intensities of Cherenkov radiations ${ }^{[12,13]}$.

Cherenkov counting was carried out with 20-ml volume polyethylene plastic (1-mm wall thickness) and low-potassium borosilicate glass sample vials ${ }^{[14]}$.

\section{Experimental suggestion}

Bottle made from polyethylene containing water and trace amount of ${ }^{90} \mathrm{Sr}$ $\left({ }^{90} \mathrm{Y}\right)$ isotopes. $\beta$-particles travel in water with light production. Therefore, the light will incident on polyethylene of the bottle. The Cherenkov radiation is emitted in the forward direction of the Beta particles $^{[15]}$.

The photonic crystal is located at polyethylene. Therefore, the medium is water and the substrate is polyethylene i.e water- photonic crystals polymer. Using water- photonic crystals- polyethylene in the vial where the blue light emitted from Cherenkov process travels in water and incident on the PCs. One-dimensional photonic crystals materials consists of Aluminum oxide $\left(\mathrm{Al}_{2} \mathrm{O}_{3}\right)$ and titanium oxide $\left(\mathrm{TiO}_{2}\right)$ with the periodicity, $\mathrm{N}=5$ which are used as a reflectors around the surface of the bottle in the system shown in Figure 1. These composite materials are characterized by high reflectivity for the target application. The intensify light is directed to the window made from high light transmission photonic crystal materials like Silicon dioxide $\mathrm{SiO}_{2} /$ Silicon Nitride $\mathrm{Si}_{3} \mathrm{~N}_{4}$ composite. Thus, the light is intensified and incident on top of the vial which has a high transmission PCs. Consequently, the intensified light gets out of the vial through the window. 


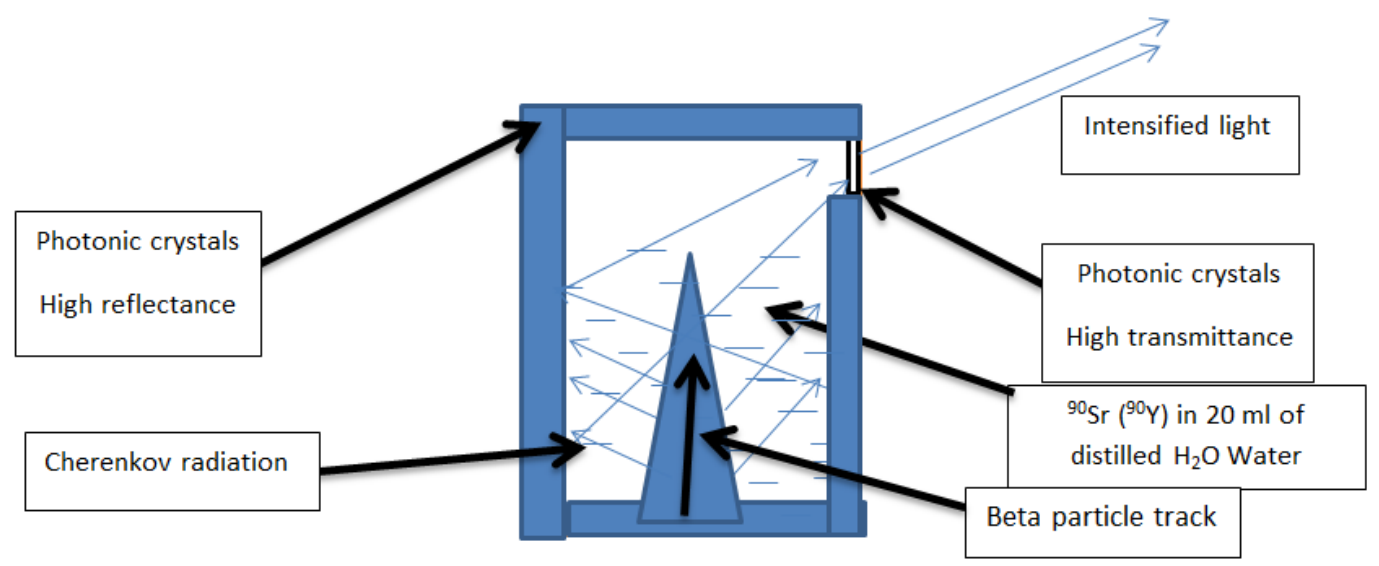

Figure 1 Schematic diagram for intensified light production by Cherenkov Effect.

\section{Theoretical Calculations}

To calculate the matrixs at the interface between the proposed materials we have used the transfer matrix (TMM) which are used for studying the electromagnetic waves propagations in the current medium which was designed as a 1DPC described in Figure 2. We have used the MATLAB software to build the convenient code for our calculations and simulation, where reflectance and transmittance has been investigated with the photonic crystal design with wavelength range between 200-900 $\mathrm{nm}$. The reflectance for $1 \mathrm{DPC}$ of $\mathrm{Al}_{2} \mathrm{O}_{3} / \mathrm{TiO}_{2}$ composite was studied at a different incident angle $(\theta)$ of the incident light, many periods $(\mathrm{N}=5)$ and different thickness of two materials $\left(\mathrm{d}_{1}, \mathrm{~d}_{2}\right)$. We assume that the $\mathrm{Al}_{2} \mathrm{O}_{3}$ refracive index is $n_{1}$ with thickness is $d_{1}$. Also the $\mathrm{TiO}_{2}$ refractive index is $\mathrm{n}_{2}$ with thickness is $\mathrm{d}_{2}$. The transmittance for $1 \mathrm{DPC}$ of $\mathrm{SiO}_{2} / \mathrm{Si}_{3} \mathrm{~N}_{4}$ composite was studied at the normal incident $(\theta)=0^{\circ}, \mathrm{N}=5$, the thickness and the refractive index of $\mathrm{SiO}_{2}$ and $\mathrm{Si}_{3} \mathrm{~N}_{4}$ are $\mathrm{d}_{1}, \mathrm{~d}_{2}, \mathrm{n}_{1}$ and $\mathrm{n}_{2}$ respectively. 


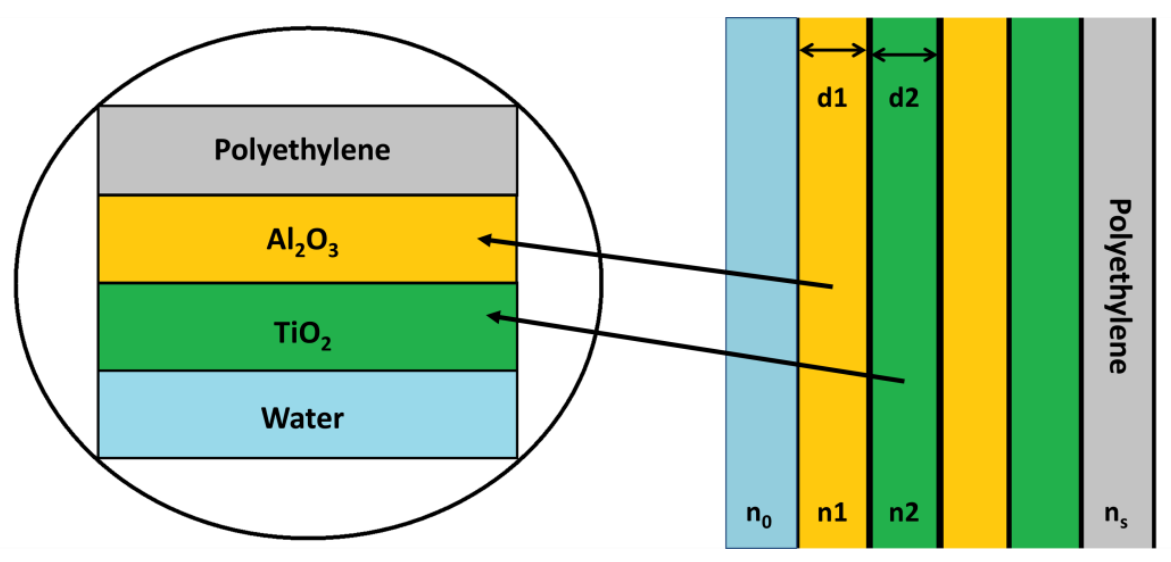

Figure 2 The $\mathrm{n}_{1}$ and $\mathrm{n}_{2}$ structures of $\mathrm{Al}_{2} \mathrm{O}_{3} / \mathrm{TiO}_{2}$ composite in $1 \mathrm{DPC}$.

In the presnt analysis, we used TMM for the theoretical calculations ${ }^{[16]}$. The electromagnetic waves interaction with 1DPCs alos treated by the characteristic matrix method where the interaction between the incident radiations and the presnt structure described by the following matrix:

$$
M_{2 \times 2}=\left(\begin{array}{ll}
M 11 & M 12 \\
M 21 & M 22
\end{array}\right)=D_{0}^{-1}\left(D_{1} P_{1} D_{1}^{-1} \quad D_{2} P_{2} D_{2}^{-1}\right)^{N} D_{s}
$$

This method treated our problem through multilayers along the $\mathrm{x}$ direction and obtained using TMM. ${ }^{[16]}$ This method is based on the analysis of the electric field interactions with the structure along the specified direction in terms of the dynamical and propagating matrices for both TM and TE waves, where the dynamical (D) matrices can be written in the following form:

$$
D=\left(\begin{array}{cc}
1 & 1 \\
n \cos \theta & -n \cos \theta
\end{array}\right) \text { for } T E \text { wave, (2) }
$$

the propagation matrices $(\mathrm{P})$ take the form:

$$
P\left(\begin{array}{cc}
\exp (i Q) & 0 \\
0 & \exp (-i Q)
\end{array}\right), \quad i=1,2,3, \ldots .(3)
$$

The reflectance $\mathrm{R}$ and transmittance $\mathrm{T}$ are described by the following expression: 


$$
T=|t|^{2}=\left|\frac{1}{M 11}\right|^{2}, \quad R=|r|^{2}=\left|\frac{M 21}{M 11}\right|^{2} .
$$

\section{Results and Discussion}

The direction $\theta$ of emitted CR obey the condition described in equation $5^{[17]}$,

$$
\cos \theta=1 / n \beta
$$

where is the reflective index of the medium is $n$ and $(\beta)=v / c$ is the relative phase velocity of the particle which can be calculated using equation 9.

Using equation 5 for ${ }^{90} \mathrm{Sr}\left({ }^{90} \mathrm{Y}\right)\left[\beta_{(0.546 \mathrm{MeV})}=0.875\right.$ and $\beta(2.284 \mathrm{MeV})=$ 0.983], respectively. The emitted Cherenkov radiation will be at angles $\left(\theta_{\max }\right)_{1}=30.85^{\circ}$ and $\left(\theta_{\max }\right)_{2}=40.1^{\circ}$ for their energies $0.546 \mathrm{MeV}$ and 2.284 $\mathrm{MeV}$, respectively. The possible angles of incident Cherenkov photons on the reflective materials which are desgined by PCs can be calculated from the follsing assumption (equation 6),

$$
\theta_{\text {incident }}=90^{\circ}-\theta_{\max }
$$

The values of incident angle ( $\left.\theta_{\text {incident }}\right)$ are about $60^{\circ}$ and $50^{\circ}$ for energies $0.546 \mathrm{MeV}$ and $2.284 \mathrm{MeV}$, respectively. Our calculations focus to investigate the reflectance at angles $50^{\circ}, 60^{\circ}, 70^{\circ}, 80^{\circ}$ and $89^{\circ}$.

The reflectance spectra at different angles $\left(50^{\circ}-89^{\circ}\right)$ for our proposed photonic crystal structure were investigated as shown in Figure 3-7. The used parameters were refractive indices $\mathrm{n}_{1}=1.43$ and $\mathrm{n}_{2}=2.65$ of Aluminum oxide $\left(\mathrm{Al}_{2} \mathrm{O}_{3}\right)$ and Titanium dioxide $\left(\mathrm{TiO}_{2}\right)$ respectively, the thicknesses of the layers were $d_{1}=150 \mathrm{~nm}$ and $\mathrm{d}_{2}=50 \mathrm{~nm}$ for $\mathrm{Al}_{2} \mathrm{O}_{3}$ and $\mathrm{TiO}_{2}$ respectively, and the periodicity for this composite was $\mathrm{N}=5$.

In Figure 3-7 we observed the calculated optical reflectance spectra for $\mathrm{Al}_{2} \mathrm{O}_{3} / \mathrm{TiO}_{2}$ photonic crystal at different incident angles $\left(50^{\circ}-89^{\circ}\right)$ using 
Cherenkov radiation. The obtained data based on the PC is calculated using $\mathrm{TMM}^{[16]}$.

At incident angle $\theta=50^{\circ}$ the width of photonic band gap (PBG) is 425 $818 \mathrm{~nm}$ with reflectivity of $99.88 \%$ as shown in Figure 3, and at Figure 4 the incident angle is $\theta=60^{\circ}$ in which the width of PBG becomes 375 $780 \mathrm{~nm}$ with reflectivity $99.98 \%$.

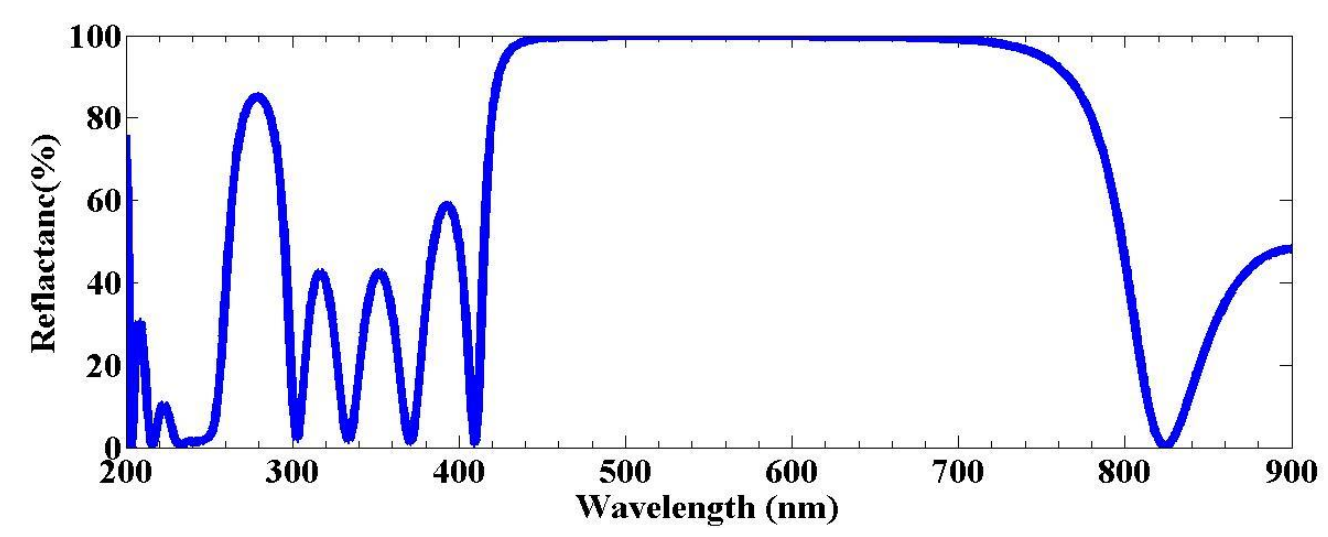

Figure 3 Reflectance spectra at $50^{\circ}$ incident angles of dielectric photonic crystal with $\mathrm{n} 1=1.43, \mathrm{n} 2=2.65, \mathrm{~d} 1=150 \mathrm{~nm}, \mathrm{~d} 2=50 \mathrm{~nm}$ and number of periods $\mathrm{N}=5$.

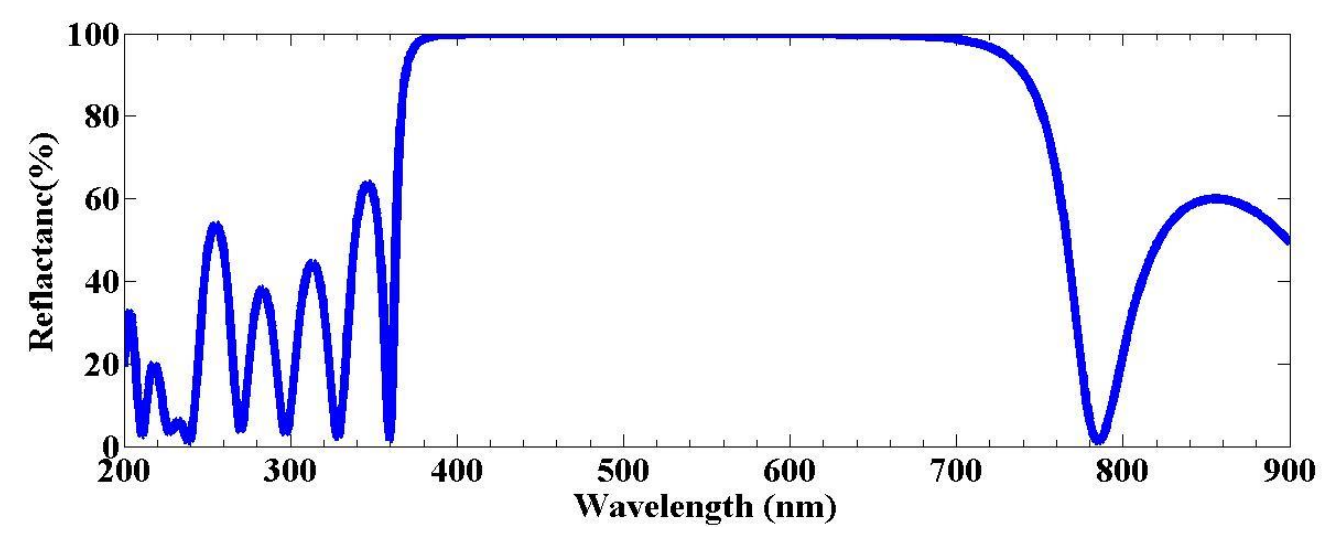

Figure 4 Reflectance spectra at $60^{\circ}$ incident angles of dielectric photonic crystal with $n_{1}=1.43, n_{2}=2.65, d_{1}=150 \mathrm{~nm}, d_{2}=50 \mathrm{~nm}$ and number of periods $\mathrm{N}=5$.

However, there is a blue shift at $\theta=70^{\circ}$ and the width of PBG is 323 $748 \mathrm{~nm}$ with reflectivity $99.98 \%$ as illustrated Figure 5. 


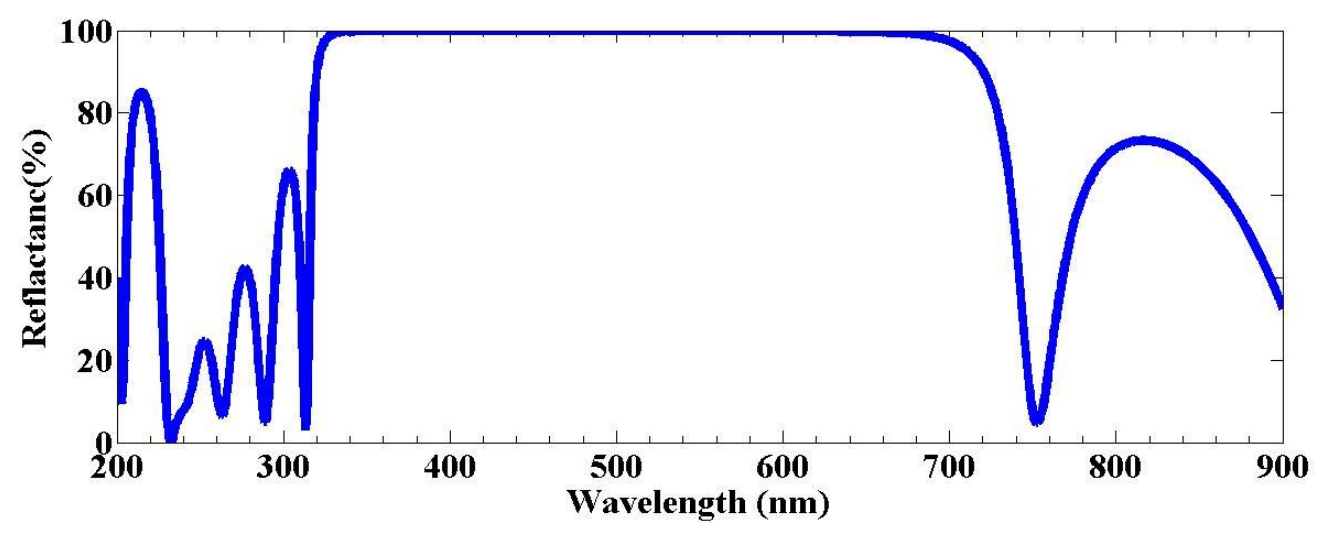

Figure 5 Reflectance spectra at $70^{\circ}$ incident angles of dielectric photonic crystal with $n_{1}=1.43, n_{2}=2.65, d_{1}=150 \mathrm{~nm}, d_{2}=50 \mathrm{~nm}$ and number of periods $\mathbf{N}=5$.

By increasing the incident angle of the electromagnetic waves at $\theta=80^{\circ}$ we noted the photonic bandgap shifted to the less wavelength. As a result, the value of reflectance for $\mathrm{Al}_{2} \mathrm{O}_{3} / \mathrm{TiO}_{2}$ is very high and can be reached to $100 \%$ in the range of photonic bandgap $290-728 \mathrm{~nm}$ at angle $\theta=80^{\circ}$ (Figure 6).

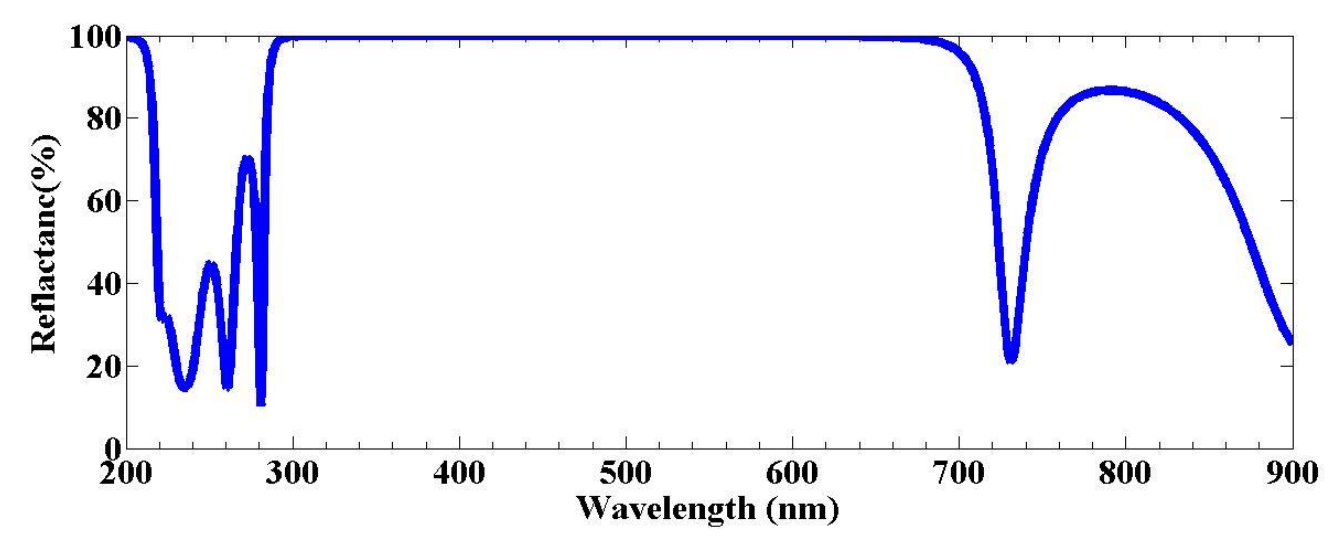

Figure 6 Reflectance spectra at $80^{\circ}$ incident angles of dielectric photonic crystal with $n_{1}=1.43, n_{2}=2.65, d_{1}=150 \mathrm{~nm}, d_{2}=50 \mathrm{~nm}$ and number of periods $\mathrm{N}=5$.

The incident angle affects the reflectance of the $\mathrm{Al}_{2} \mathrm{O}_{3} / \mathrm{TiO}_{2}$ photonic crystal where increasing the incident angle of the electromagnetic waves causes an increasing the blue shift of the band gaps. As a result at angle $\theta$ $=89^{\circ}$ (Figure 7), the value of reflectance for $\mathrm{Al}_{2} \mathrm{O}_{3} / \mathrm{TiO}_{2}$ is very high and 
can be reached to $100 \%$ in the range of photonic band gap from $270-715$ nm.

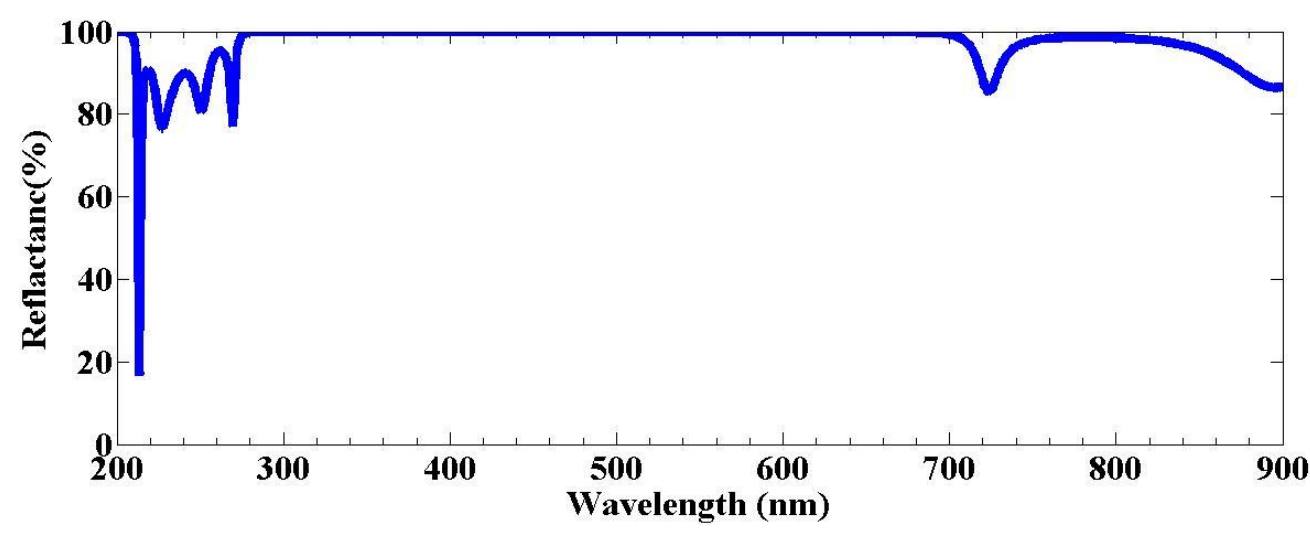

Figure 7 Reflectance spectra at $89^{\circ}$ incident angles of dielectric photonic crystal with $n_{1}=1.43, n_{2}=2.65, d_{1}=150 \mathrm{~nm}, d_{2}=50 \mathrm{~nm}$ and number of periods $\mathbf{N}=5$.

Therefore, for all mentioned angles, we observed about $99 \%$ reflectivity was obtained by $\mathrm{Al}_{2} \mathrm{O}_{3} / \mathrm{TiO}_{2}$ photonic crystal at a wide band of wavelengths 400 - $600 \mathrm{~nm}$ (Cherenkov photons wavelengths) for the present angles.

Due to the high reflectance of the current photonic crystals composite, the reflection of all possible photons emitted from Cherenkov radiation could be intensified at the output gate as depicted in Figure 1.

Table 1 shows the relation between incident angle of electro magnetic wave which produced from Cherenkov phenomena and shift wavelength, when the incidence angle increase photonic band gap blue shifted due to Brew-ster effect at the interface between low and high index layers.

Table 1: the wavelength values which are shifted at different incident angles

\begin{tabular}{|c|c|}
\hline Incident angle $\boldsymbol{( \theta}^{\mathbf{}} \mathbf{)}$ & Shift wave length(nm) \\
\hline $50^{\circ}$ & $\mathbf{4 2 5 - 8 1 8} \mathbf{~ n m}$ \\
\hline $60^{\circ}$ & $375-780 \mathbf{n m}$ \\
\hline $70^{\circ}$ & $323-748 \mathbf{~ n m}$ \\
\hline $80^{\circ}$ & $290-728 \mathbf{~ n m}$ \\
\hline $89^{\circ}$ & $270-715 \mathbf{~ n m}$ \\
\hline
\end{tabular}


The intensified photons can pass easily through the gate made from a high transmittance photonic crystal Silicon dioxide $\mathrm{SiO}_{2} /$ Silicon Nitride $\mathrm{Si}_{3} \mathrm{~N}_{4}$ composite, which shows an excellent light transmission especially at wavelengths ranges $400-600 \mathrm{~nm}$ as shown in Figure 8.

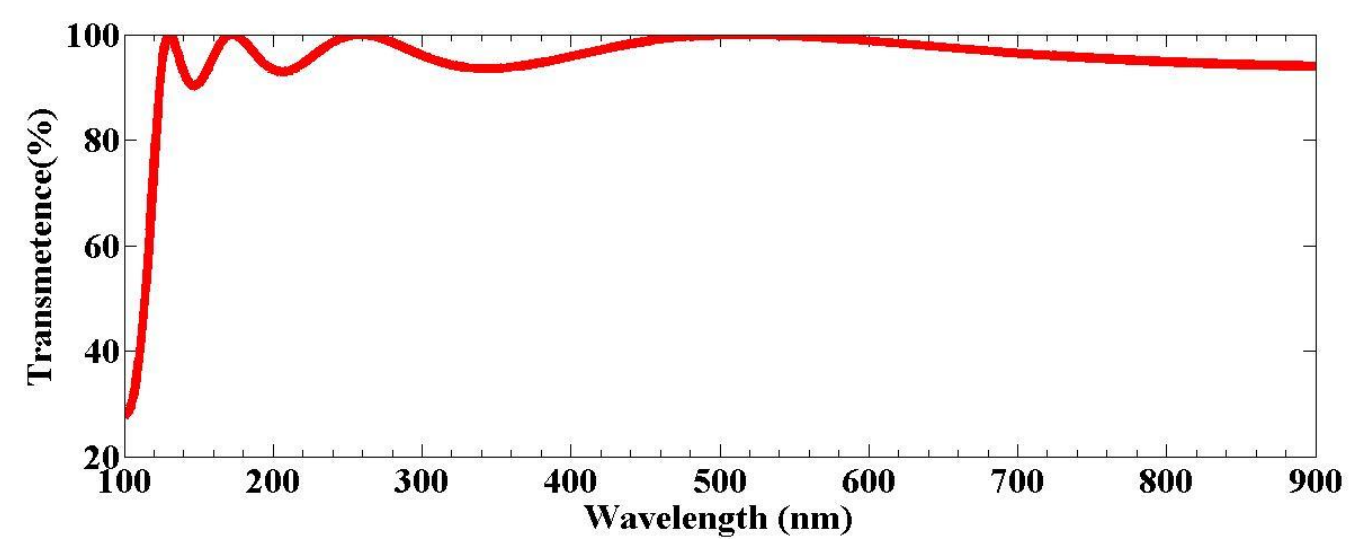

Figure 8 Transmittance spectra for photonic crystal $\mathrm{SiO}_{2} / \mathrm{Si}_{3} \mathrm{~N}_{4}$ composite at $\theta=0, \mathrm{~N}=5, \mathrm{n}_{1}=1.55, \mathrm{n}_{2}=2.0167, \mathrm{~d}_{1}=20 \mathrm{~nm}$ and $\mathrm{d}_{2}=10 \mathrm{~nm}$.

The used parameters for the periodic photonic structure described in Figure 9 were as following : refractive indices, $\mathrm{n}_{1}=1.55$ and $\mathrm{n}_{2}=2.0167$ of Silicon dioxide $\mathrm{SiO}_{2}$ and Silicon Nitride $\mathrm{Si}_{3} \mathrm{~N}_{4}$ respectively, the thicknesses of the layers were $d_{1}=20 \mathrm{~nm}$ and $d_{2}=10 \mathrm{~nm}$ for $\mathrm{SiO}_{2}$ and $\mathrm{Si}_{3} \mathrm{~N}_{4}$ respectively, and the periodicity for this composite was $\mathrm{N}=5$ and at normal incident $\theta=0^{\circ}$. Due to high transmittance, the intensified output beam will pass from the window side to the other side without losing its original power. 


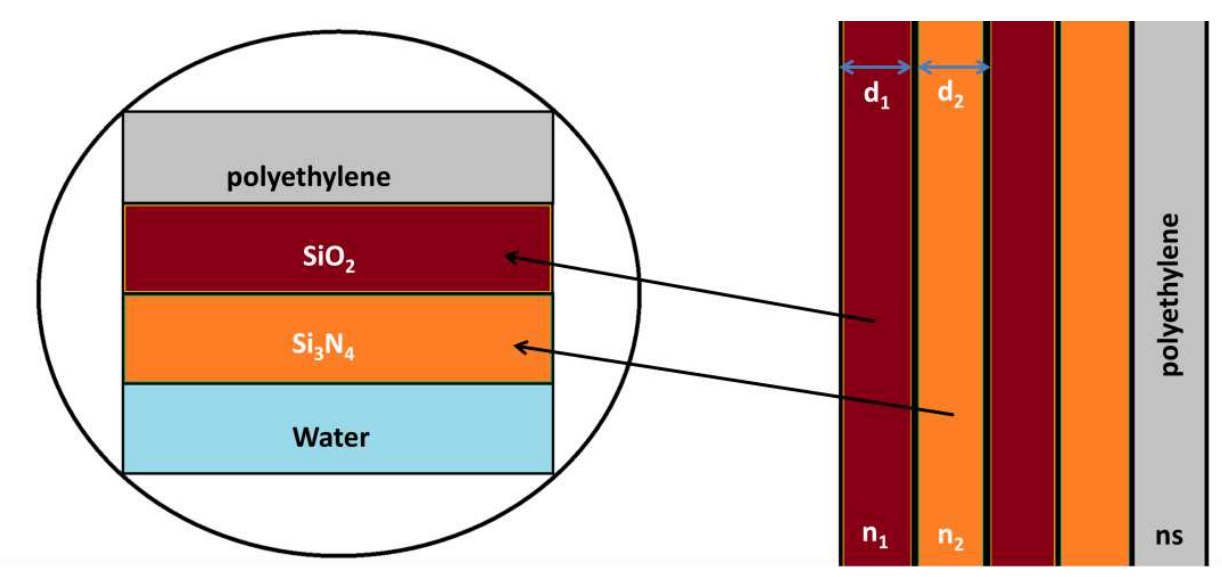

Figure 9 The $\mathrm{n}_{1}$ and $\mathrm{n}_{2}$ structures of $\mathrm{SiO}_{2} / \mathrm{Si}_{3} \mathrm{~N}_{4}$ composite in $1 \mathrm{DPC}$ as atransmittence

\subsection{Number of Cherenkov photons and power} calculation

The total number of photons for each Beta $\mathrm{k}(\mathrm{E})^{[13]}$ emitted can be calculated for the individual beta particle energy can be obtained using equations (7-9).

$$
\begin{aligned}
& \beta=\sqrt{1-\left(\frac{1}{E / 511+1}\right)^{2}} \\
& \frac{d k}{d x}=2 \pi \alpha\left(\frac{1}{\lambda_{1}}-\frac{1}{\lambda_{2}}\right)\left(1-\frac{1}{n^{2} \beta^{2}}\right) \\
& k(E)=\int_{E_{t h}}^{E} \frac{d k}{d x} \frac{1}{\rho d E / d x} d E
\end{aligned}
$$

Where $\beta=v / c$ and $d k / d x$ is the number of photons per $\mathrm{nm}, \alpha$ is the fine structure constant $(\alpha=1 / 137), \mathrm{n}$ is the medium refractive index (water=1.333). Also, $\lambda_{1}=400 \mathrm{~nm}$ and $\lambda_{2}=600 \mathrm{~nm}$ are the lower and upper limit of the wavelength region for Cherenkov radiation, $\rho$ is the 
density of water (medium) which equal $1 \mathrm{~g} / \mathrm{cm}^{3}, \mathrm{dE} / \mathrm{dx}$ is the electron stopping power in water for the given energies ${ }^{[18,19]}$ and $E$ is the energy of incident beta particles.

From the calculations using the reported equations $7-9$, the number of emitted photons for beta particle energies $0.546 \mathrm{MeV}$ and $2.284 \mathrm{MeV}$ are $\mathrm{k}\left(\mathrm{E}_{1}\right)=18$ photons and $\mathrm{k}\left(\mathrm{E}_{2}\right)=243$ photons, respectively.

Finally, the total number of photons emitted per second (n) from Cherenkov radiation of radioactive source ${ }^{90} \mathrm{Sr}$ of activity $(\mathrm{A}=1 \mathrm{Ci})$ can be calculated using equation 10 .

$$
n=(k(E 1)+k(E 2)) * A
$$

Consequently, the $n$-value was calculated and founded to be $9.66 \times 10^{12}$ photons/sec.

\subsubsection{Power calculations}

Equations 11 and 12 are used to calculate the total power of emitted photons from Cherenkov radiation by radioactive source ${ }^{90} \mathrm{Sr}\left({ }^{90} \mathrm{Y}\right)$ of $\operatorname{activity}(\mathrm{A}=1 \mathrm{Ci})$.

The energy of Cherenkov emitted photon of wavelength $\lambda=420 \mathrm{~nm}$ can be calculated from equation 11 and the energy is $E=4.73 \times 10^{-19}$ Joule.

$$
\bar{E}=h v=h \frac{C}{\lambda}
$$

Where $\bar{E}$ is average energy, h is plank constant $\left(6.625 \times 10^{-34} \mathrm{~J} . \mathrm{sec}\right), \mathrm{C}$ is the speed of light $=3 \times 10^{17} \mathrm{~nm} / \mathrm{sec}$ and the photon wavelength is $\lambda=420$ $\mathrm{nm}$. Then, the total power was calculated using equation $12^{[20]}$ and the value was $4.52 \mu \mathrm{Watt}$.

$$
\text { Power }=n \times \bar{E} \times 0.99
$$


Where the value 0.99 is the reflectivity.

\subsection{Cherenkov radiation as an electric power source}

The intensified Cherenkov light may fall on the GaAs solar cell at the output gate as shown in Figure 10.

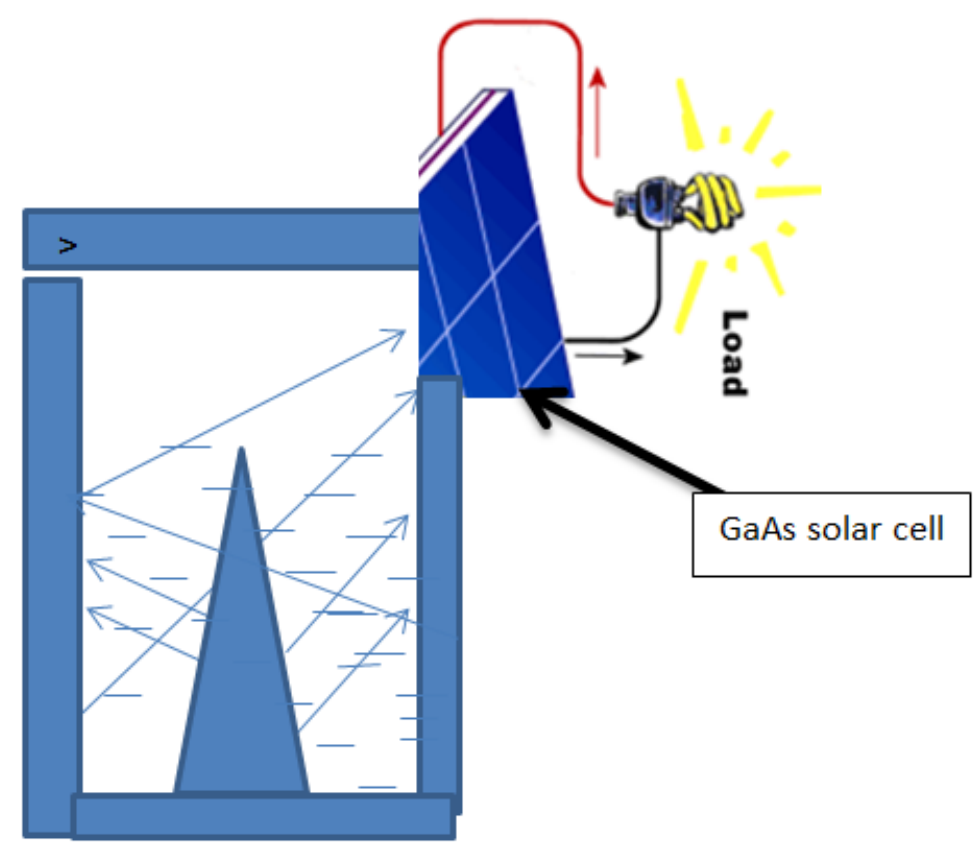

Figure 10 Schematic diagram for intensified light produced by Cherenkov effect and GaAs solar cell.

The spectral response of the GaAs was displayed by S. Mazzucato et al ${ }^{[21]}$, where the results shows external quantum efficiency (EQE) $25 \%$ $55 \%$ for wavelength range $400-900 \mathrm{~nm}$ as reported in the refrence ${ }^{[20]}$. Also, the EQE of the GaAs device was reported $19 \%-74 \%$ at a wavelength range of $375-450 \mathrm{~nm}^{[22]}$. So the GaAs solar cell device is convenient for absorption of the Cherenkov light, but the more efficient device is the triple-junction solar cell which used for output power investigation.

The absolute efficiency of cell energy conversion $(\eta)^{[20]}$

$$
\eta(\%)=\frac{P_{\text {out }}}{P_{\text {in }}}
$$


Where $\mathrm{P}_{\text {out }}$ is the output power from the cell and $\mathrm{P}_{\mathrm{in}}$ is the total power. For the mentioned GaInP/GaAs/ Ge solar cell, where the input power $\left(P_{\text {in }}\right)$ $4.52 \mu$ watt, the output power $\left(P_{\text {out }}\right)$ was found $1.45 \mu$ watt. If used small activity for the radioactive source ${ }^{90} \operatorname{Sr}\left({ }^{90} \mathrm{Y}\right), \mathrm{A}=1 \mathrm{mCi}$, then the output power was found 1.45 nwatt. Applications for output micro/nano-watt power source are nuclear batteries ${ }^{[20],[23],[24],[25]}$, medical instrumentation systems, scientific and engineering instruments, and also radio and radar receivers $^{[26],[27],[28]}$.

\section{Conclusions}

Reflective layers made by using PCs in a one-dimensional array consists of $\mathrm{Al}_{2} \mathrm{O}_{3} / \mathrm{TiO}_{2}$ which were used as reflectors in the vial in the Cherenkov system to intensify the light. The reflectivity of this array reached $100 \%$ in Cherenkov wavelength $(400-600 \mathrm{~nm})$ at different incident angles $\left(50^{\circ}-\right.$ $89^{\circ}$ ). Many reflections are useful to intensify the Cherenkov light which passes through the window made from high transmittance PCs in 1D ( $\left.\mathrm{SiO}_{2} / \mathrm{Si}_{3} \mathrm{~N}_{4}\right)$. These layers are located on the wall of the vial from polyethylene. This system helps to intensify the blue light produced from Cherenkov radiation. The intensified light has power equal

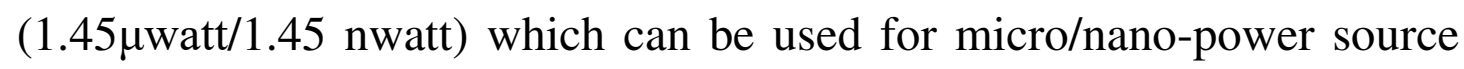
applications.

\section{References}

${ }^{1}$ Aly A.H., Eissa M.F. INCREASE IN THE REFLECTED INTENSITY OF X-RAY FILMS USING PHOTONIC CRYSTALS. Surf. Rev. Lett. (2017); 24(8).

${ }^{2}$ Eissa, M. F., and Arafa H. Aly. "Improve the efficiency of scintillation detectors using reflectors based on photonic crystals arrays." Journal of Electromagnetic Analysis and Applications, 9, 2014).

${ }^{3}$ Claus Grupen, Irène Buvat, Handbook of Particle Detection and Imaging, SpringerVerlag Berlain Heidelberg, (2012), p. 453-741. 
${ }^{4}$ M. F. Eissa and A. H. Aly, J. Comput. Theor. Nanosci. 10 (2013) 1527.

${ }^{5}$ A. H. Aly, S. A. El-Naggar and H. A. Elsayed, Opt. Express 23 (2015) 15038.

${ }^{6}$ X. Gu, X. F. Chen, Y. P. Chen, X. L. Zheng, Y. X. Xia and Y. L. Chen, Opt. Commun. 237 (2004) 53.

${ }^{7}$ Cerenkov P.A., a. Visible light from clear liquids under the action of gamma radiation. C.R. Dokl. Akad. Nauk, SSSR 2 (8), (1934), 451-454.

${ }^{8}$ MF. L'Annunziata. Handbook of radioactivity analysis, 3rd, Elsevier Inc, (2012), p. 241-248.

${ }^{9}$ Gruhn, C.R., Ogle, W. In: Peng, C.-T., Horrocks, D.L., Alpen, E.L.(Eds.), Liquid Scintillation Counting, Recent Applications and Development, vol. 1. Academic Press, New York and London, (1980), pp. 357-374.

${ }^{10}$ Burden, Daniel L., and Gary M. Hieftje. "Cerenkov radiation as a UV and visible light source for time-resolved fluorescence." Analytical chemistry 70.16 (1998): 3426-3433.

${ }^{11}$ Belcher, E. H. The luminescence of irradiated transparent media and the Cherenkov effect. I. The luminescence of aqueous solutions of radioactive isotopes. Proc. Royal Soc. (1953). A216, 90-102.

12 Jang, K.W.; Yoo, W.J.; Shin, S.H.; Shin, D.; Lee, B. Fiber-optic Cerenkov radiation sensor for proton therapy dosimetry. Opt. Express (2012), 20, 13907-13904.

${ }^{13}$ Kyoung Won Jang, Sang Hun Shin, Seon Geun Kim, Jae Seok Kim, Wook Jae Yoo, Young Hoon Ji and Bongsoo Lee, Measurement of Cerenkov Radiation Induced by the Gamma-Rays of Co-60 Therapy Units Using Wavelength Shifting Fiber , Sensors (2014), 14, 7013-7025.

${ }^{14}$ M.F. L'Annunziata, C.J. Passo Jr. Cherenkov counting of yttrium-90 in the dry state; correlations with phosphorus-32 Cherenkov counting data, Applied Radiation and Isotopes 56 (2002) 907-916.

15 Mietelski J.W., Gaca P., Bielec J. Optimization of counting conditions for Cerenkov radiation by LSC. In: Chalupnik, S., Scho“nhofer, F,.Noakes, J. (Eds.), LSC 2005, Advances in Liquid Scintillation Spectrometry. Radiocarbon, University of Arizona, Tucson, (2006) pp. 13-17.

${ }^{16}$ P. Yeh, Optical Waves in Layered Media (John Wiley\& Sons, New Jersey, (2005).

${ }^{17}$ Frank I.M. Optics of light sources moving in refractive media. Science 131, (1960), 702-712.

${ }^{18}$ A. Knapitsch, E. Auffray, C. W. Fabjan, J.-L. Leclercq, P. Lecoq, X. Letartre and C. Seassal, Nucl.Instr. Methods Phys. Res. A 628 (2011) 385.

${ }^{19} \mathrm{https} / / /$ physics.nist.gov/cgi-bin/Star/e_table.pl

${ }^{20}$ Prelas, Mark A., Charles L. Weaver, Matthew L. Watermann, Eric D. Lukosi, Robert J. Schott, and Denis A. Wisniewski. "A review of nuclear batteries." Progress in Nuclear Energy 75 (2014): 117-148.

${ }^{21}$ Mazzucato, S., et al., Dilute nitride and GaAs nipi solar cells. Nanoscale. research letters, 2012. 7(1): p. 1-5. 
22. Zhang, Z., et al., Use the indirect energy conversion of the phosphor layer to improve the performance of nuclear batteries. Energy Technology, 2018. 6(10): p. 1959-1965.

${ }^{23}$ Zhao, C., Liu, A., Bai, S., \& Zhao, Y.. Understanding efficiency differences of betavoltaic batteries measured by electron gun mimicked source and radioactive $\beta$ source. Applied Physics Letters, (2020), 117(19) doi:10.1063/5.0028450.

${ }^{24}$ Murphy, J. W., Frye, C. D., Henderson, R. A., Stoyer, M. A., Voss, L. F., \& Nikolic, R. J. Demonstration of a three-dimensionally structured betavoltaic. Journal of Electronic Materials, (2021), doi:10.1007/s11664-020-08611-y.

${ }^{25}$ Moayedi, H., Hajibaba, S., Afarideh, H., Ghergherehchi, M., \& Mohamadian, M. Optimization of beta radioluminescent batteries with different radioisotopes: A theoretical study. Nuclear Science and Engineering, (2021),

${ }^{26}$ Schmickl, S., Faseth, T. \& Pretl, H. Microwatt power management: challenges of on-chip energy harvesting. Elektrotech. Inftech. (2020). https://doi.org/10.1007/s00502-020-00859-w

${ }^{27}$ Nielsen-Lönn, M., Angelov, P., Wikner, J.J. et al. Self-powered micro-watt level piezoelectric energy harvesting system with wide input voltage range. Analog Integr Circ Sig Process 98, 441-451 (2019). https://doi.org/10.1007/s10470-018-1259-5

${ }^{28}$ Al-Shorman, Mohammad \& Al-Kofahi, Majd \& Al-Kofahi, Osameh. A practical microwatt-meter for electrical energy measurement in programmable devices. Measurement and Control. 51. (2018). 


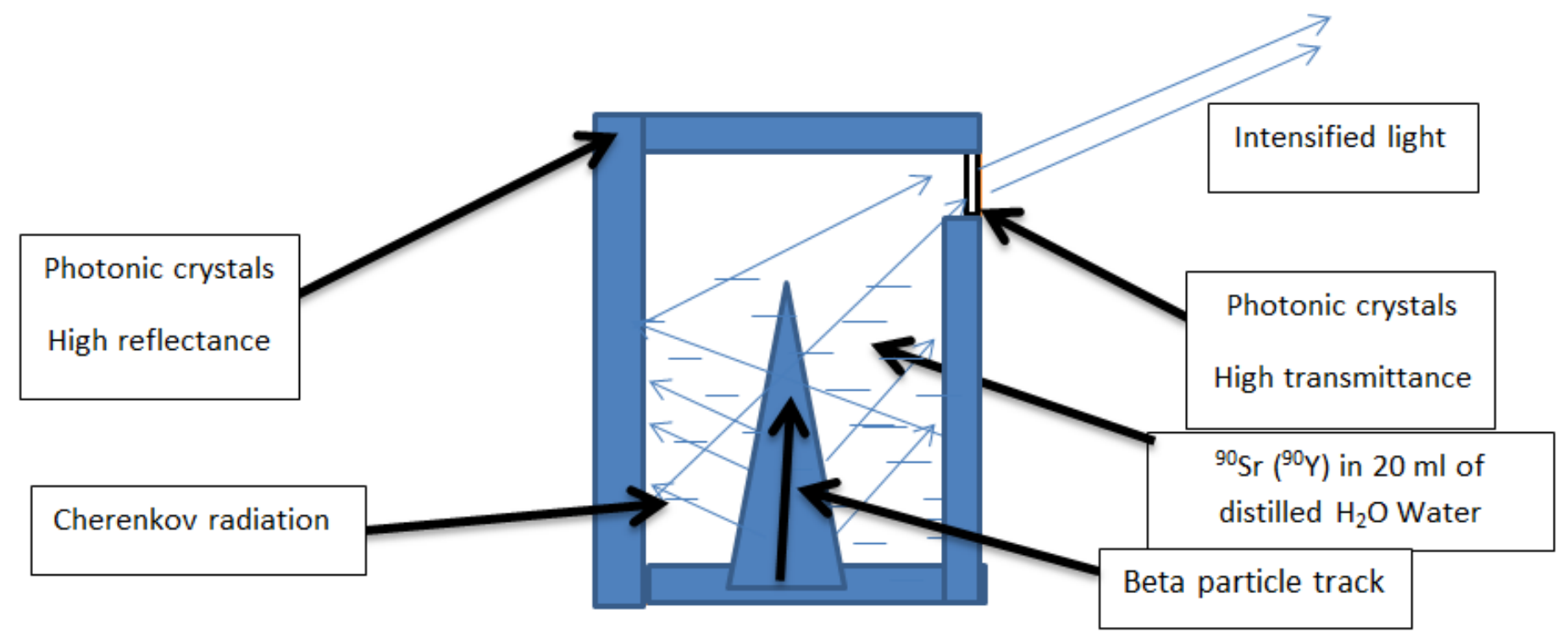

\section{Figure 1}

Schematic diagram for intensified light production by Cherenkov Effect.

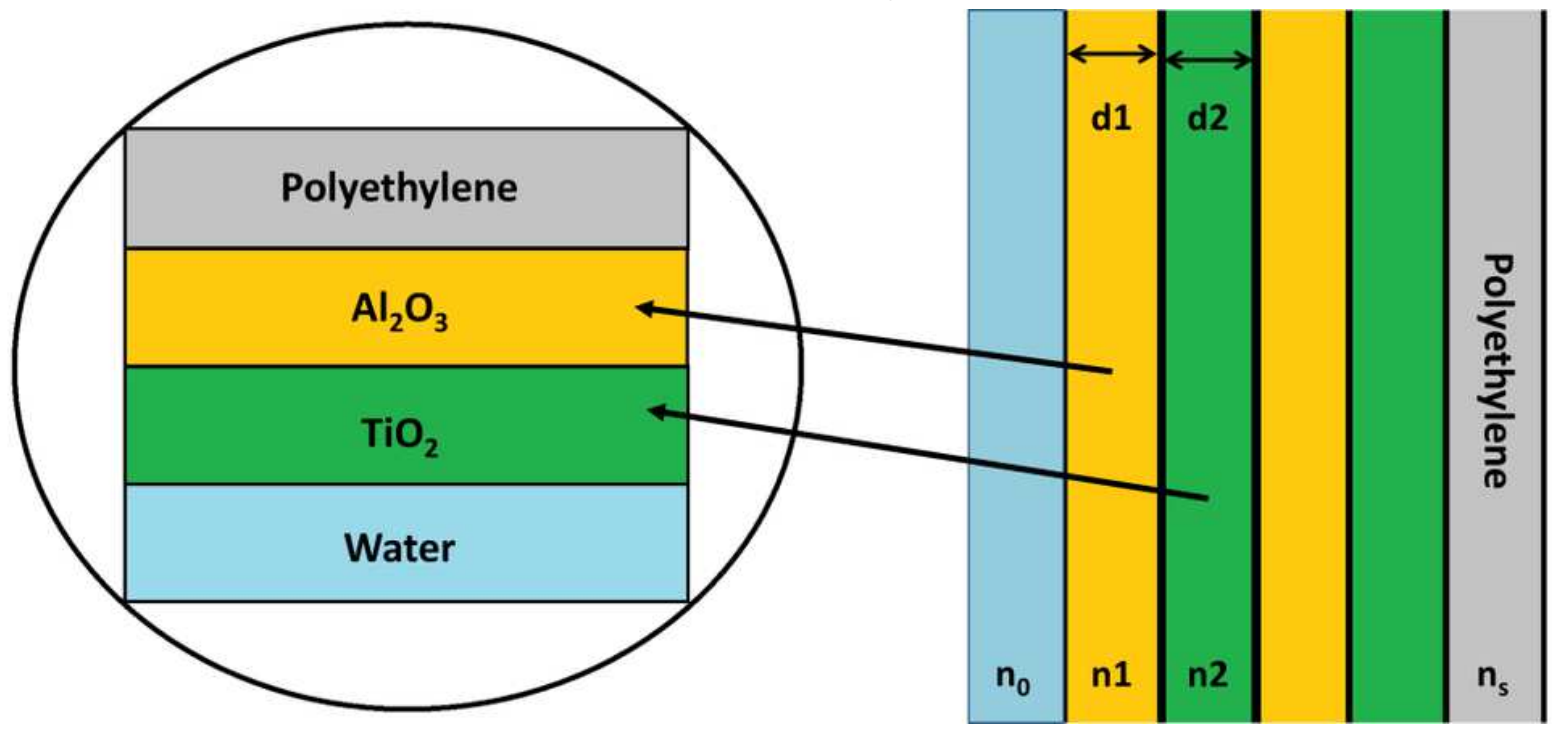

Figure 2

The $\mathrm{n} 1$ and $\mathrm{n} 2$ structures of $\mathrm{Al} 2 \mathrm{O} 3 / \mathrm{TiO} 2$ composite in 1 DPC. 


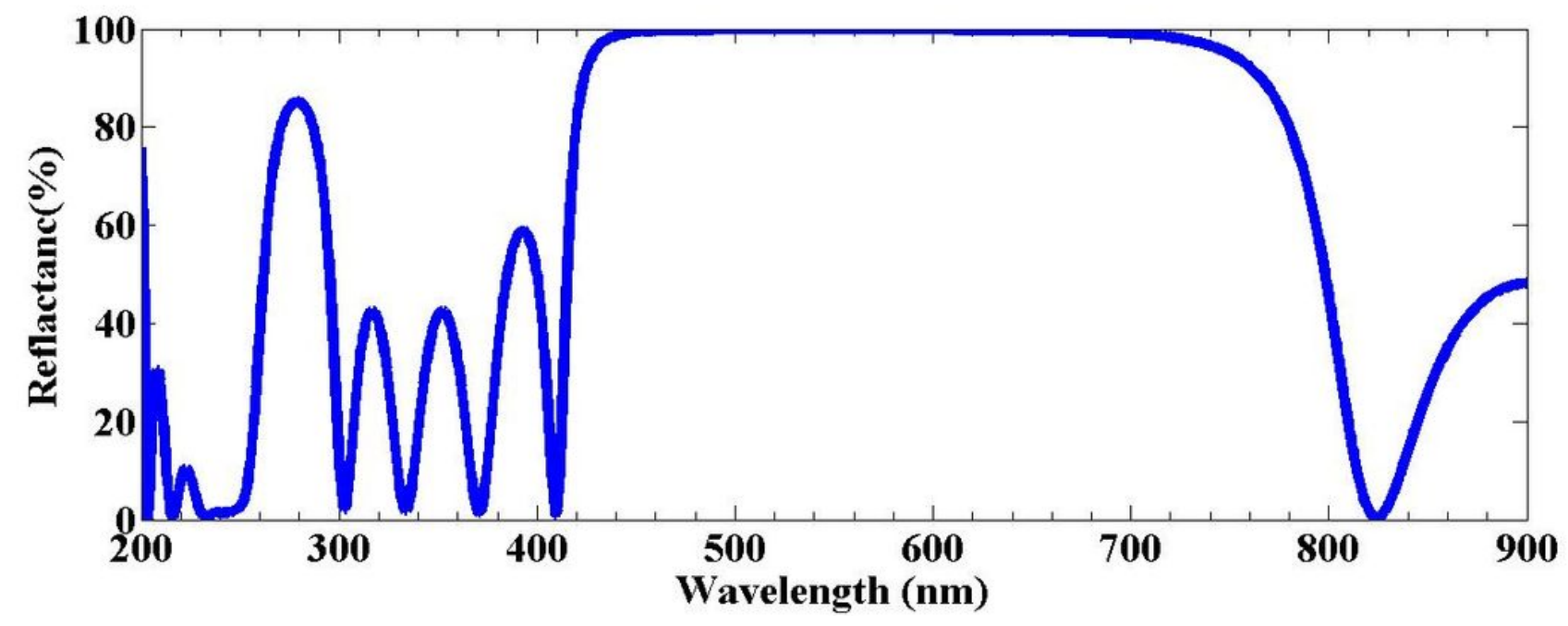

Figure 3

Reflectance spectra at $50 \mathrm{o}$ incident angles of dielectric photonic crystal with $\mathrm{n} 1=1.43, \mathrm{n} 2=2.65, \mathrm{~d} 1=$ $150 \mathrm{~nm}, \mathrm{~d} 2=50 \mathrm{~nm}$ and number of periods $\mathrm{N}=5$.

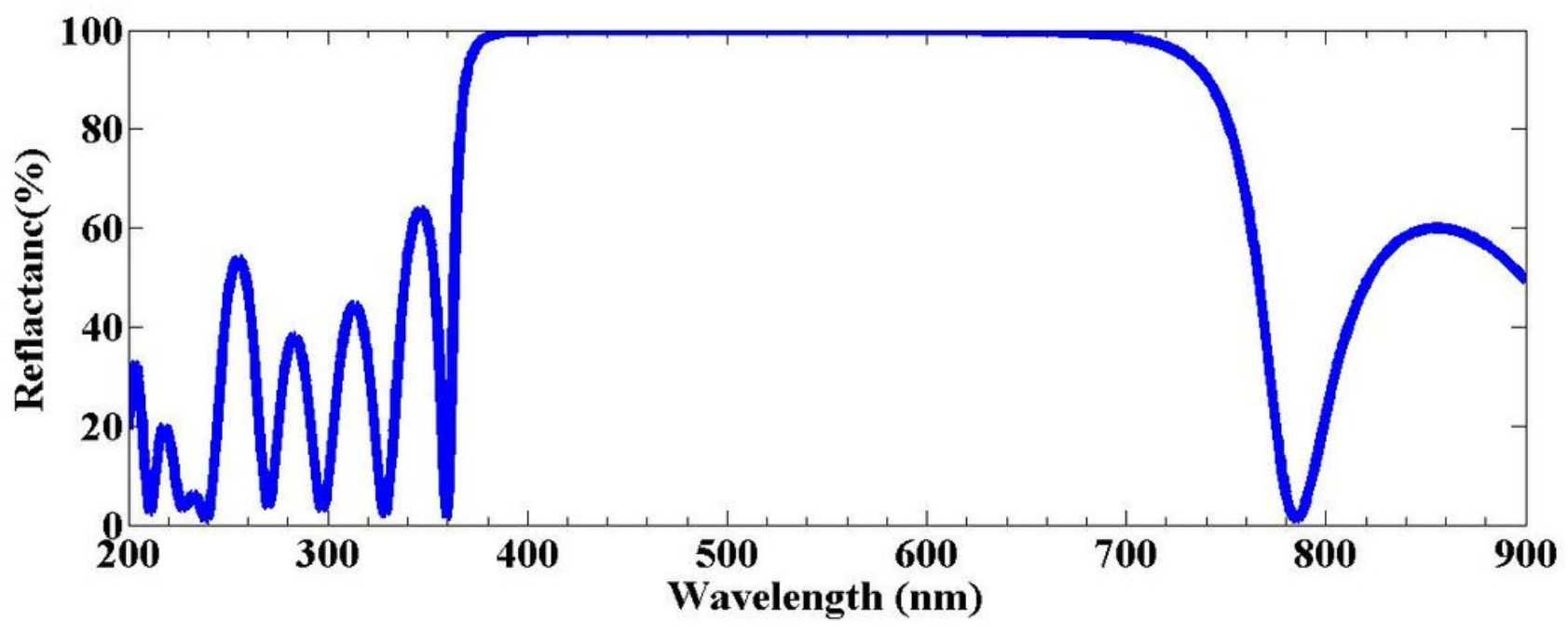

Figure 4

Reflectance spectra at $60 \mathrm{o}$ incident angles of dielectric photonic crystal with $\mathrm{n} 1=1.43, \mathrm{n} 2=2.65, \mathrm{~d} 1=$ $150 \mathrm{~nm}, \mathrm{~d} 2=50 \mathrm{~nm}$ and number of periods $\mathrm{N}=5$. 


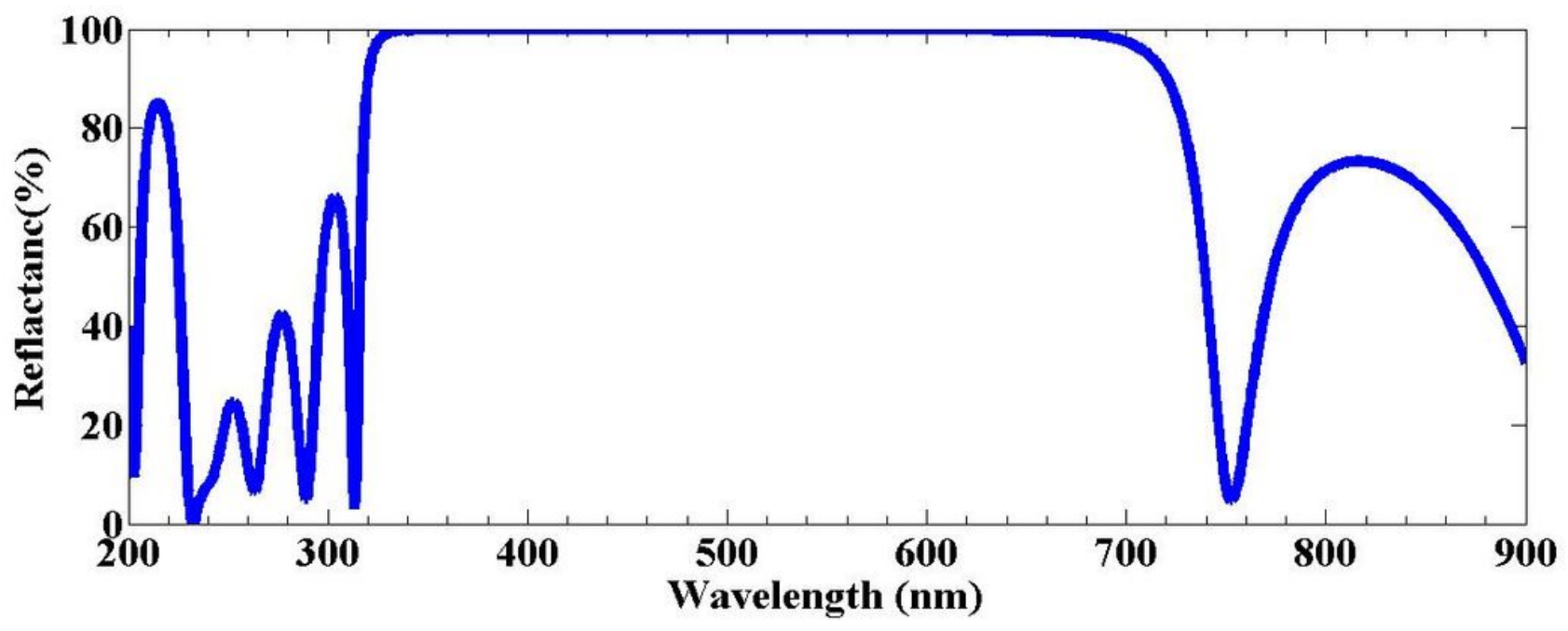

Figure 5

Reflectance spectra at 70o incident angles of dielectric photonic crystal with $\mathrm{n} 1=1.43, \mathrm{n} 2=2.65, \mathrm{~d} 1=$ $150 \mathrm{~nm}, \mathrm{~d} 2=50 \mathrm{~nm}$ and number of periods $\mathrm{N}=5$.

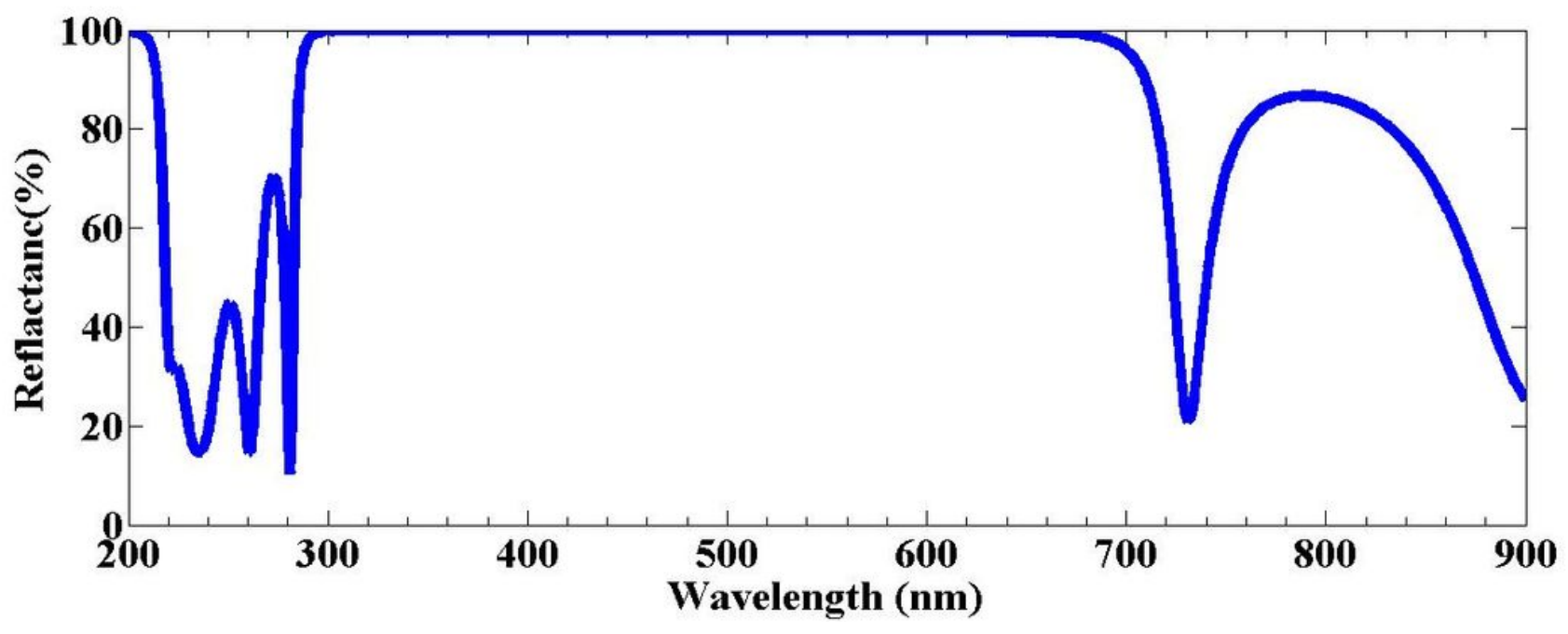

Figure 6

Reflectance spectra at $80 \mathrm{o}$ incident angles of dielectric photonic crystal with $\mathrm{n} 1=1.43, \mathrm{n} 2=2.65, \mathrm{~d} 1=$ $150 \mathrm{~nm}, \mathrm{~d} 2=50 \mathrm{~nm}$ and number of periods $\mathrm{N}=5$. 


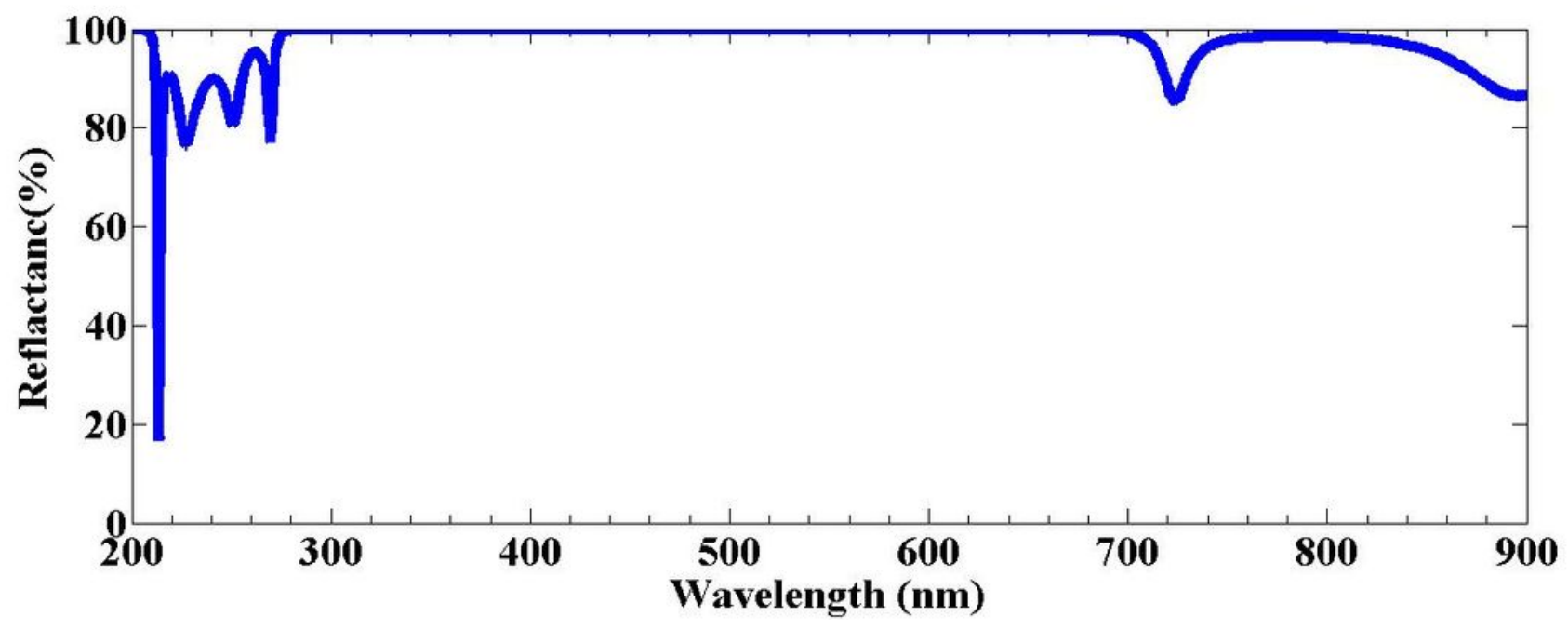

Figure 7

Reflectance spectra at $89 \mathrm{o}$ incident angles of dielectric photonic crystal with $\mathrm{n} 1=1.43, \mathrm{n} 2=2.65, \mathrm{~d} 1=$ $150 \mathrm{~nm}, \mathrm{~d} 2=50 \mathrm{~nm}$ and number of periods $\mathrm{N}=5$.

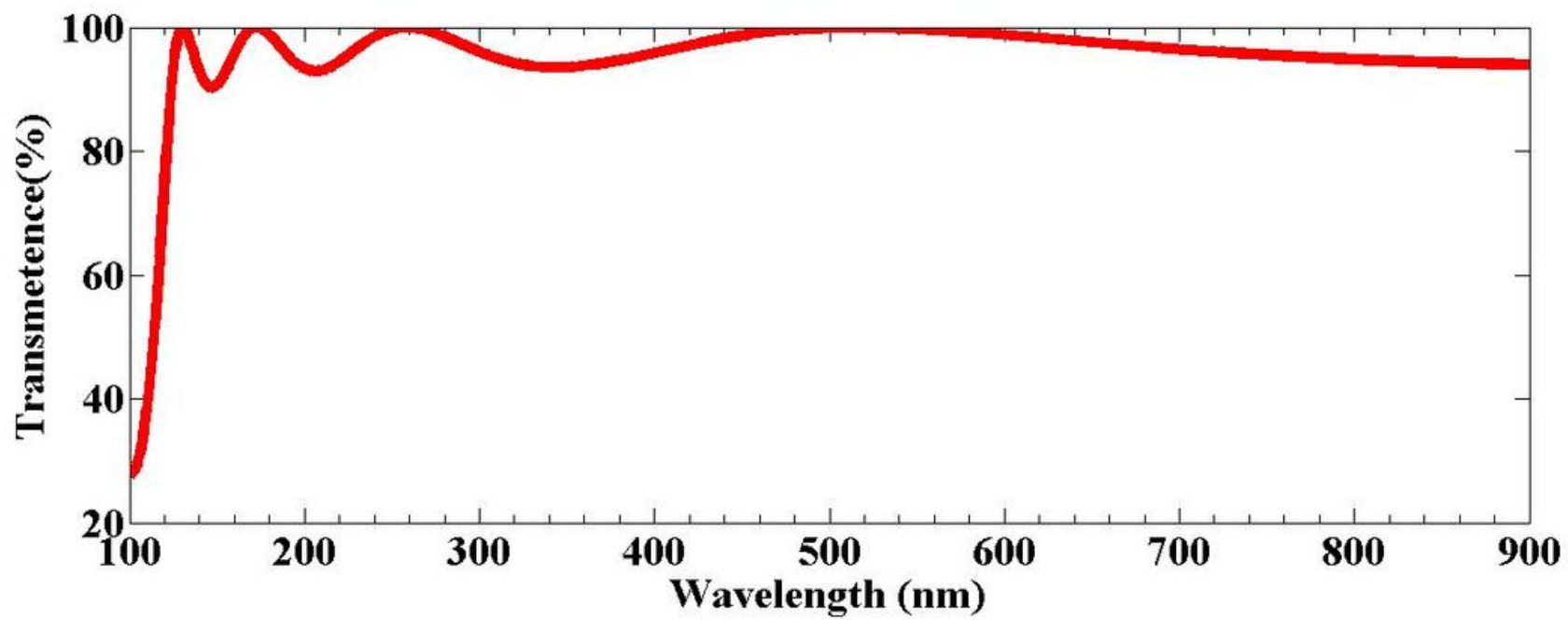

Figure 8

Transmittance spectra for photonic crystal SiO2 /Si3N4 composite at $\theta=0, N=5, n 1=1.55, n 2=2.0167$, $\mathrm{d} 1=20 \mathrm{~nm}$ and $\mathrm{d} 2=10 \mathrm{~nm}$. 


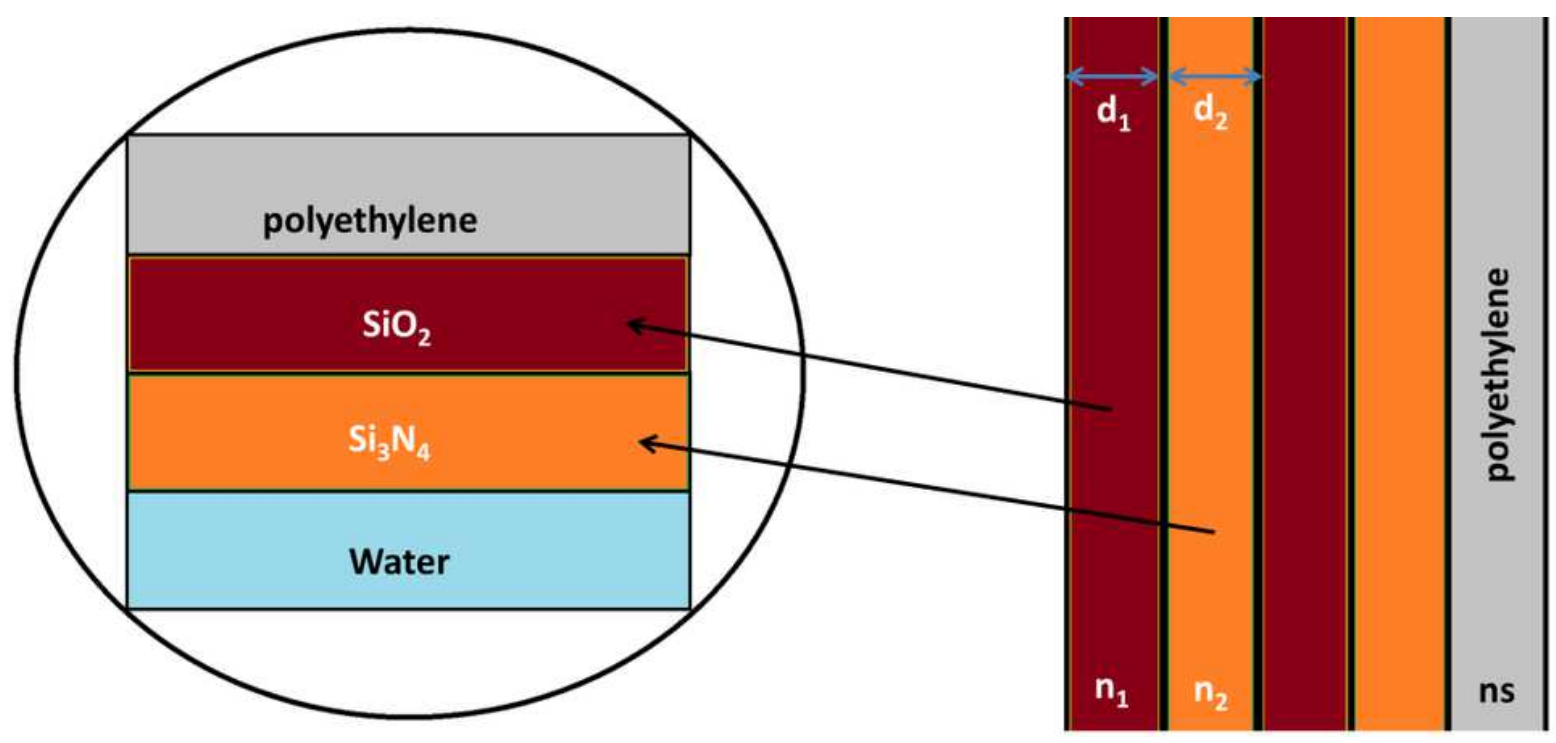

Figure 9

The $\mathrm{n} 1$ and $\mathrm{n} 2$ structures of SiO2/ Si3N4 composite in 1 DPC as atransmittence

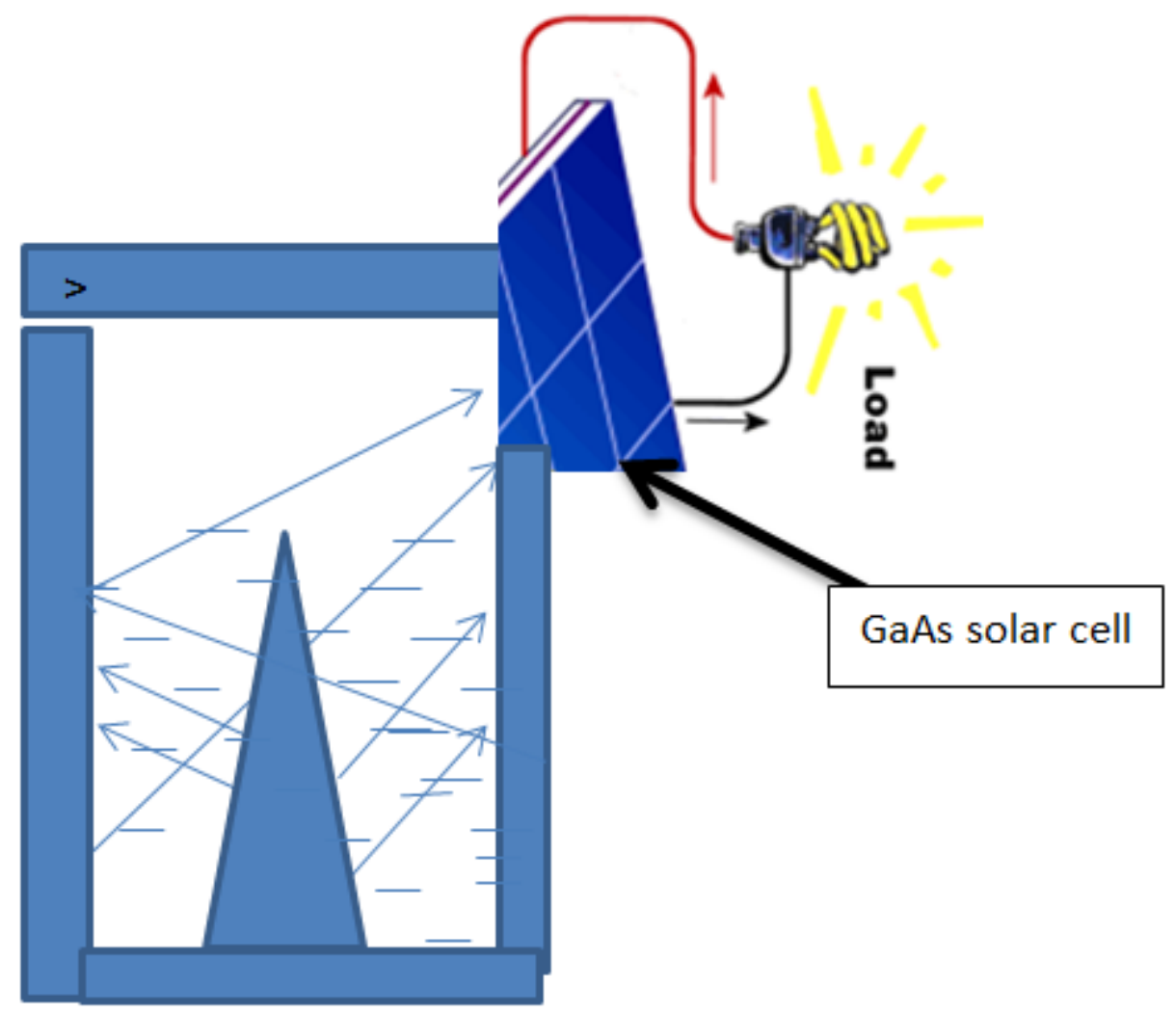

Figure 10

Schematic diagram for intensified light produced by Cherenkov effect and GaAs solar cell. 